\begin{tabular}{l} 
SCIENCE \& TECHNOLOGY \\
Journal homepage: http://www.pertanika.upm.edu.my/ \\
\hline PERTANIKA
\end{tabular}

\title{
Behavioural Model for Decision-Makers' towards the Intention to Adopt Green Information Technology: A Preliminary Study
}

\author{
Abba Kyari Buba ${ }^{1,2 *}$ and Othman Ibrahim ${ }^{1}$ \\ ${ }^{1}$ Department of Information Systems, School of Computing, Universiti Teknologi Malaysia, 81310 Skudai, \\ Johor, Malaysia \\ ${ }^{2}$ Faculty of Social and Management Science, Yobe State University, Nigeria
}

\begin{abstract}
This preliminary survey investigates and validates the measurement model of factors influencing decision makers' intentions to adopt Green information technology (Green-IT) in manufacturing sectors in Nigeria. The Norm Activation Model (NAM) and Theory of Planned Behaviour (TPB) were used to explore the factors that could influence decisionmakers' intention in adopting Green-IT. Using constructs from the NAM and TPB, this survey proposes a model for identified behavioural factors. A quantitative research approach with a data collection and analysis plan using a cross-sectional survey design was adopted. A sample of 30 decision-makers in the top three manufacturing industries in Nigeria was selected using a purposive sampling procedure for participation in the study. The data collected was analysed using Partial Least Square Structural Equation Modelling (PLS-SEM) to test the proposed model. The model was validated in two phases: (i) Initial Measurement Model and (ii) Modified Measurement Model. Findings revealed that Green-

ARTICLE INFO

Article history:

Received: 4 February 2021

Accepted: 5 July 2021

Published: 28 October 2021

DOI: https://doi.org/10.47836/pjst.29.4.09

E-mail addresses:

bkoriyell@gmail.com (Abba Kyari Buba)

othmanibrahim@utm.my (Othman Ibrahim)

*Corresponding author

IT Attitude, Subjective Norm, Ascription of Responsibility, Awareness of Consequences, Personal Norm, Environmental Concern, and Perceive Behavioural Control were the key elements of the behavioural intention model to adopt Green-IT, with 31 indicators having factor loadings of $>0.5$, adequate internal consistency reliability, CR $>0.7$, and Cronbach's Alpha, $>0.7$. The result revealed convergent validity, and acceptable discriminant validity was assessed using AVE $>0.5$ and Fornell-lacker's criterion.
\end{abstract}


The results from the full-scale study would contribute to developing a context-specific model to examine Green-IT adoption in developing nations.

Keywords: Adoption, green-IT, manufacturing industries managers, norm activation model, theory of planned behaviour

\section{INTRODUCTION}

Green-IT is about the genuine utilisation of IT to control the environmental sustainability of its operations, products, services, resources, systems, and production processes (Esfahani et al., 2015; Yang et al., 2019). According to De Luis et al. (2015) and Asadi et al. (2019), Green-IT is the solution that contributes actively to the reduction of pollution emissions (De Luis et al., 2015). Furthermore, Green-IT has been mentioned to provide solutions that could sustain a decrease in environmental footprints. Thus, enabling the firms to accept and adopt the changes in environmental regulations and expand the firm's competitiveness over time (Chen \& Chang, 2014a; Chen \& Chang, 2014b; Przychodzen et al., 2018; Yacob et al., 2018).

Green IT can be defined as Information Technology (IT), and Information System (IS) products, services, and practices to achieve sustainable development while focusing on energy proficiency for the used IT infrastructure (Anthony et al., 2020). Also, from other studies, Green-IT is regarded as the appropriate utilisation of IT for managing environmental sustainability to maximise the positive human behavioural impacts on the environment (Asadi et al., 2019; Esfahani et al., 2015; Guo et al., 2019; Yang et al., 2019). This process is achievable through designing, application, production, operation, and IT disposal, and products and services during their life cycle (Akman \& Mishra, 2015; Seidel et al., 2013; Buba \& Ibrahim, 2020; Yang et al., 2019). Green-IT solutions could sustain a decrease in environmental footprints, enable firms to accept and adopt the changes in environmental regulations, and expand the firm's competitiveness over time (Chen \& Chang, 2014a; Chen \& Chang, 2014b; Przychodzen et al., 2018; Yacob et al., 2018). Hence, Green-IT promotes work efficiency, business processes, deals with e-waste, IT-related emissions, and lower energy consumption (Dalvi-Esfahani et al., 2017a; Dalvi-Esfahani et al., 2017b; Sani et al., 2016). The forecasted benefits include competitive advantage, corporate sustainability in both the environment and the society (Gandhi et al., 2018; Kong et al., 2016; Nallusamy et al., 2016; Yang et al., 2019), lower waste and pollution and hence, energy conservation (Maruthi \& Rashmi, 2015; Rehman \& Shrivastava, 2013; Woo et al., 2014). Thus, this is achievable if Green-IT is made possible through its incorporation into the daily activities of an organisation.

Developing nations are lagging in technology diffusion, adoption, and implementation because of several challenges. A study mentions that this is because of internal or 
external organisational practices (Singh \& Sahu, 2020), while another study mentions cost issues, lack of knowledge, and awareness of sustainable development (Wang et al., 2018). A study conducted by Chen \& Chang ( 2014a \& 2014b) states that Greenhouse effects have increasingly become a major global issue due to concerns for environmental sustainability. Furthermore, there has been an establishment of the sustainability pillars (environmental, social, and economic). The international community urges companies to consider innovative methods and practices to sustain the environment (Aboelmaged \& Hashem, 2019). Similarly, government policies, laws, and shareholders' pressures have been affecting the industries in trying to improve actions on environmental sustainability (Brandvik et al., 2019; Juschten et al., 2019). By integrating IT, innovations can shape the environmental circumstances and enable people to apply them (Huda, 2019; Przychodzen et al., 2018; Yacob et al., 2018). Research agrees that there is a benefit in the environment, economically and socially, which leads to sustainable development if Green-IT is utilised (Wang et al., 2018).

Besides, it entails managerial and human practices and organisational policies for sustainability (Singh \& Sahu, 2020). However, despite Green-IT being able to handle environmental issues for economic fulfilment (Asadi et al., 2019; Chen \& Chang, 2014a; Chen \& Chang, 2014b; Guo et al., 2019), there has not been a fast adoption rate by manufacturing industries in developing countries to leverage these benefits. As a result, there is a gap in the adoption of Green-IT in developing countries, especially Nigeria. Furthermore, the effect of human behaviour in the adoption of Green-IT is an issue. Evolving technologies suffer numerous issues involving people's behaviour, which is equally critical for environmental sustainability (Chen \& Chang, 2014a; Chen \& Chang, 2014b; Yacob et al., 2018). Thus, the main goal of this study is to establish decision-makers' opinions for intention to adopt Green-IT.

\section{The Objectives of the Study}

This study concentrates on the following objectives:

1. To identify factors that influence the decision-makers to have intention in GreenIT adoption.

2. To analyse the relationship between the identified factors for the intention to adopt Green-IT.

3. To propose a behavioural model for the intention of adopting Green-IT to support the decision-makers.

\section{Theoretical Background}

To study the adoption of Green-IT by decision-makers, the author proposes a theoretical model based on a thorough review of the relevant literature. Based on research, cost-benefit 
analyses do not adequately forecast pro-environmental action because their implementation decisions require value judgments, and well-known frameworks of individual adoption are not the best options for clarifying Green-IT incorporation in firms. The combination of the Theory of Planned Behaviour (TPB) and Norm Activation Model (NAM), which is developed in the sense of prosocial and environmentally responsible conduct and considerate conduct, will provide a more robust theoretical model that would clarify the implementation of Green-IT, as it involves value judgments and cost evaluations.

According to Ajzen and Fishbein (1980), the Theory of Planned Behaviour (TPB) emanates from the Theory of Reasoned Action (TRA), whereby TRA mentions that actions are entirely under volitional control, that individual behaviour results from the intent to do a behaviour. The intentions are determined by perceived behavioural control, attitudes, and subjective norms, as stated in the Theory of Planned Behaviour (TPB). In social and pro-environmental behaviour, the TPB is considered one of the most influential theories. Armitage and Conner (2001) have validated TPB in the pro-environmental behaviour context (Arvola et al., 2008; Asadi et al., 2015). The TPB is a well-established model to predict behaviour across various contexts and settings (Pavlou \& Sawy, 2006). A general model is used to explain most human behaviours (Ajzen, 1991).

The Norm Activation Model (NAM) was developed about altruistic behaviour (Schwartz, 1977). The main component is personal norms which are achieved as being morally obligated rather than intent. They are utilised in NAM for individual behaviour prediction. From the model, the determination of personal norms occurs in two ways, awareness of consequences resulting from performing a particular behaviour and sensitiveness of control for indulging in a specific behaviour (Schwartz, 1977). Several studies posit NAM as a moderator model, while others use it for mediation (Onwezen et al., 2013). This theory has been most used to predict individual behaviour. The assumption is that personal norm drives a person's behaviour (Schwartz, 1977). Furthermore, being aware of the consequences, including ascription of responsibility, is important in initiating an individual's polite behaviour (Park \& Ha, 2014).

Based on two concepts, TPB and NAM is an integrated theoretical model, which has been applied to environmental issues in previous studies. By including personal norms in the TPB model, predictability was increased when altruistic attitudes were evaluated (Arvola et al., 2008; Burns \& Roberts, 2013; Kim \& Hwang, 2020; Rezaei et al., 2019). Therefore, the NAM model addresses the flaw of the TPB, which is a lack of focus on the personal standard. As this research aims to examine the implementation of Green-IT policies within organisations based on the objective normative context of decision-makers, NAM has been selected for this research. In line with this, many works of literature have verified the efficiency of prediction in environmental behaviour using some information system theories like TPB and NAM (Asadi et al., 2015). These studies have identified that 
when TPB and NAM are combined as mediators, they influence personal norms. Other studies have suggested that to identify behavioural intent. Actual behaviour must be an indicator (Akman \& Mishra, 2014).

The researchers almost agreed that studying the intention of individuals would help organisation policymakers to identify how individuals can think and behave. Therefore, this paper aims to study the determinant of organisation management's intention in adopting Green-IT to their workplace.

\section{Proposed Research Model}

The inceptive for adopting Green-IT intention was proposed. More so, it defined the factors and hypothesised the relationships among the model constructs. It commenced by pointing out some previous studies, which analysed the conceptual Green-IT adoption model development. A comprehensive review of the given constructs of TPB and NAM, which positively impacts the adoption of Green-IT within Nigerian manufacturing industries, has been realised. A pilot study was carried out to ensure the reliability of the instruments before the main data gathering. Figure 1 shows the proposed model.

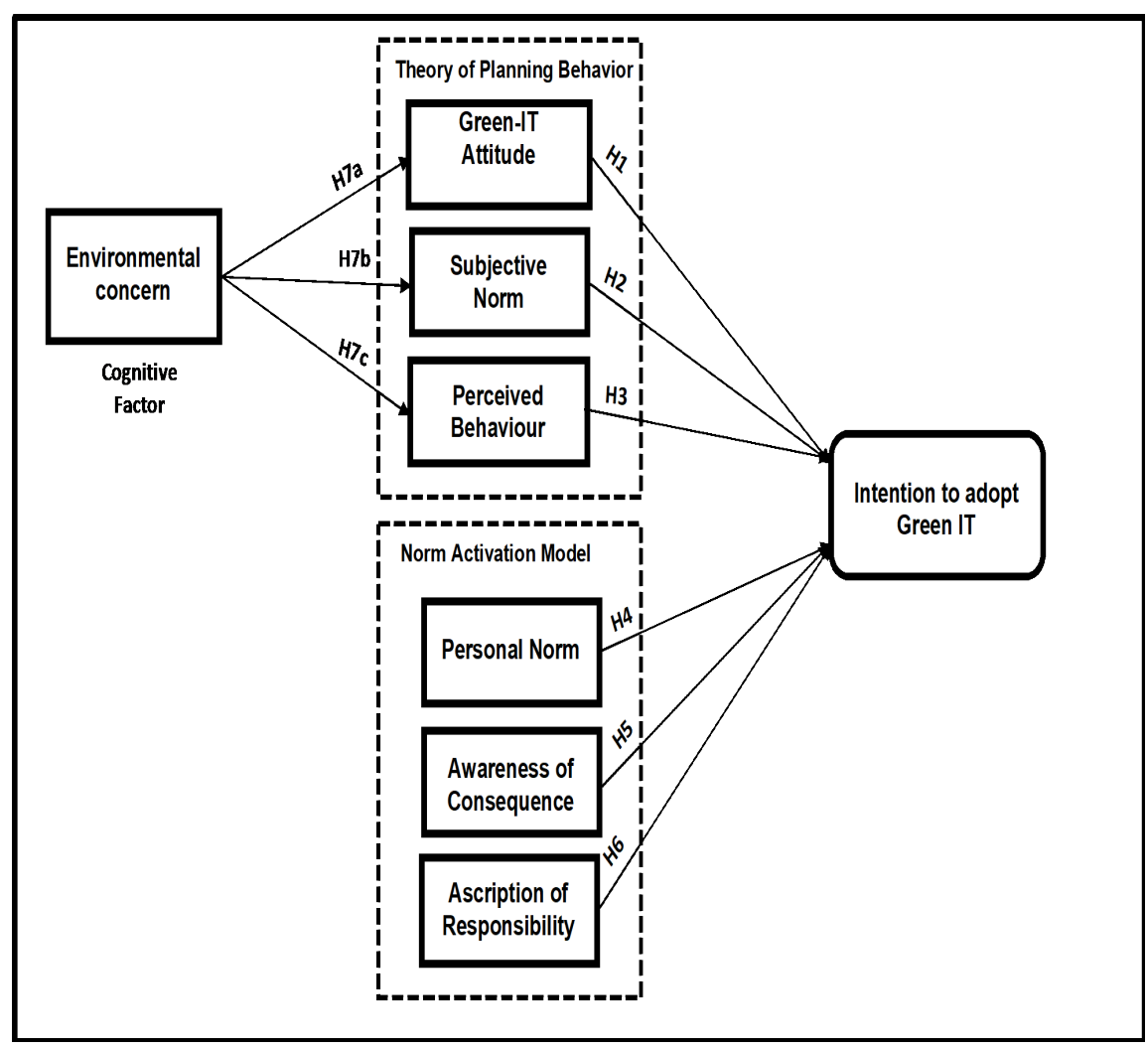

Figure 1. Initial proposed model 


\section{Hypotheses Development}

Hypotheses 1: Attitude to Green-IT. The understanding of the benefit of Green-IT in solving environmental concerns by individuals has become protracted. The general public is more likely encouraged to develop a significant attitude considering the newly updated and acquired knowledge, which is also favourable towards Green-IT in recent times (Akman \& Mishra, 2014; Ojo et al., 2019). Additionally, Bodur and Sarigöllü (2005) described that one of the best analysts of behaviour is their feelings and perception towards that particular behaviour (Reyes et al., 2013). Administrators of organisations and established businesses with a perception towards sustainability is a significant element to be used in attaining awareness on Green-IT challenges and related opportunities (Anthony Jr, 2019; Molla et al., 2008).

Previous researches have empirically reported that moral norm is a positive and significant element of the recognised concern and problematic awareness; likewise, the moral norm is an essential aspect of social behaviour or attitude (Chen \& Tung, 2014; Steg \& de Groot, 2010; Zhang et al., 2013). For example, it has been discovered that personal norm is a key factor that affects the assignment of responsibility and awareness level consequences (Ramstein et al., 2019). These identified moral obligations have an essential role to play in shaping favourable behaviour towards the environment. Following the Green-IT adoption, it can be recommended that as more business leaders are aware of the unfavourable consequences of environmental concerns, the higher they become more obliged to develop favourable behaviour towards the environment, thereby improving their potential to adopt Green-IT. Henceforth, based on these assertions, the researcher proposes the hypothesis below:

Hypothesis 1: The Attitude of Managers towards Green-IT will positively affect the intention to adopt Green-IT.

Hypotheses 2: Subjective Norm. The term subjective norm can be understood as a community burden involved in a specific behaviour (Ajzen, 1991). They influence behavioural intentions and are regarded as stimulants of the personal norm. Several empirical types of research have examined subjective norms' influence on the intention to purchase green commodities using the TPB (Zhang et al., 2019). Thus, this indicates that personal norms are influenced by other social environments and external support (Juschten et al., 2019; Koo et al., 2011). The term subjective norm is also considered an individual's attitude or perception about other important peoples' perception of their ability to perform specific tasks or behaviour exhibited in question. It means that an individual has thought about the simplicity or difficulty of a task or performing behaviour within the environment (Dezdar, 2017; Juschten et al., 2019). Previous investigations have confirmed the influence of the subjective norm on the intention or behavioural intention based on the 
TPB and the TRA models (Ainin et al., 2015; Ajzen, 1991; Chow \& Chen, 2009). A study conducted by Ainin et al. (2015) reported that the subjective norm is an essential factor in the possibility of mobile financing or banking adoption. The author indicates that a person who has perceived higher social pressure to implement Green-IT has a high positive and significant intention towards adopting it. Consequently, the researcher decides on this premise to develop the hypothesis stated below:

Hypothesis 2: Subjective norm will positively influence managers' intention to adopt Green-IT.

Hypotheses 3: Perceived Behaviour Control. Behavioural control as perceived by an individual is considered an essential aspect of TPB, also referred to as simplicity or ease of performing specific behaviours or otherwise (Lopes et al., 2019). The above assertion agrees with Ajzen (1991), who opined that the level of an individual's perceived behavioural control and behavioural intention correlation or association depends on the form of behaviour and the environmental factor (Asadi et al., 2019). In several past studies, Perceived Behavioural Control (PBC) was represented by several sub-factors, which included nature of the resources, time, and perceived level of uncertainty and inconveniences attached to action (Lin \& Huang, 2012; Lopes et al., 2019; Sujata et al., 2019; Zhao et al., 2014).

Conversely, other scholars discovered entirely different relationships between PBC and product purchase intention. According to the scientific investigations, Zhang et al. (2019) mention that PBC and intention to purchase green products have no relationship. On the other hand, the study by Nasri and Charfeddine (2012) reveals that PBC specifies individual motives that are affected by one's perception of ease or difficulty of a particular behaviour and the perception of an individual towards successful performance of an activity or task. The PBC can affect the behaviour either directly or inversely via the intention of that particular behaviour. As established by past empirical studies, this research considers that the stronger PBC of an individual, the higher his probability of performing a specific task or behaviour. Thus, these lead to the following hypothesis:

Hypothesis 3: Perceived behaviour control will positively affect the managers' intention to adopt Green-IT.

Hypotheses 4: Personal Norm. Personal Norm (PN) refers to a feeling of moral commitment to undertake or avoid undertaking a particular behaviour or activity (Schwartz \& Davis, 1981). Green-IT or issues related to the environment need the moral aspect of a person to exhibit a particular behaviour towards the environment, especially a favourable one (Asadi et al., 2019). Additionally, Harland et al. (2007) presume that prosocial or pro-environment behaviours of individuals are determined by their norms rather than by personal effect or benefit and cost evaluation. Therefore, PN is a specific behaviour 
that needs to be prompted before assuming a position of relevance or responsibility in a community. Numerous researchers who studied intentions towards environmentally friendly behaviours stress that the direct predictor of an intention is the PN (Asadi et al., 2019).

Many studies have found that the critical factor affecting various pro-environment behaviours is a personal norm. For instance, it was reported that there is a strong association between PN and environmentally friendly behaviours in a general understanding (Abrahamse \& Steg, 2009), definite environmental concerns such as conservations and green community, and a purchase (Asadi et al., 2019). Therefore, the following is hypothesised:

Hypothesis 4: The Personal Norm of managers will positively affect the intention to adopt Green-IT.

Hypotheses 5: Awareness of Consequences. The second variable to declare prosocial behaviour in NAM is Awareness of Consequences (AC). The AC refers to a situation where an individual becomes aware of how results affect others (Asadi et al., 2015; de Groot \& Steg, 2009). Empirical studies have shown that persons with the express knowledge of the negative effect of environmental conditions on their lives have a favourable attitude towards becoming more environmentally friendly by adopting pro-environmental behaviours. For example, Asadi et al. (2019) suggested that every individual must be aware of the results of their environmental behaviour, especially in the future. The literature has further established that the individual awareness consequences are positively and significantly related to environmentally friendly behaviour (Agag, 2019; Harland et al., 2007). Therefore, once specific individuals became aware of the negative effect of environmental situations, they have a higher possibility of becoming more environmentally conscious and thereby adopting pro-environmental behaviour. In related research, Lauper et al. (2014) concluded that in consideration of imbibing and accepting eco-innovation, a positive, significant relationship exists between individual awareness of adverse consequences of the environmental situation and pro-environmental behaviour. Moreover, Dalvi-Esfahani et al. (2017a \& 2017b) reported that a positive relationship which is also significant exists between personal norms and awareness of adverse consequences of the environmental concerns reveal an essential link between these variables. Thus, the researcher proposed the following hypothesis:

Hypothesis 5: Managers' awareness of consequences will positively influence the intention to adopt Green-IT.

Hypotheses 6: Ascription of Responsibility. Another critical variable in NAM is the Ascription of Responsibility (AR), as it affects prosocial behaviour among individuals. The ascription of responsibility is the feeling that an individual is developed towards a commitment to perform prosocial behaviour (Asadi et al., 2019). Following NAM 
(Schwartz, 1977), the AR is a motivating factor for an individual to have a moral obligation and zeal to perform favourable environmental behaviour in addition to its impacts on environmentally friendly behaviours. Related empirical research conducted by Willuweit (2009) revealed an AR as a significant predictor of environmentally friendly behaviour. In similar research, Zhang et al. (2013) concluded that, based on the data obtained from the electricity users, AR increases their behaviour towards the environment. Thus, they become environmentally friendly and develop positive behaviour towards saving electricity. Other similar studies, such as de Groot and Steg (2009) and Han et al. (2015), showed that AR is essential in developing a person's moral capacity and motivating pro-social behaviour. Hence, the sixth hypothesis is developed as follows:

Hypothesis 6: Managers' AR will positively influence behavioural intention to adopt Green-IT.

Hypotheses 7: Environmental Concern. The available literature established a strong fact that Environmental Concern (EC) is an attitude towards environmental protection exhibited by an individual in a specific period (Zhang et al., 2019). The EC also refers to a universal perception or behaviour that triggers an individual to engage in activities that adequately protect the environment (Zhang et al., 2019). This attitude or concern is an essential aspect that influences people's behaviour to become pro-environment or environmentally friendly. With the recent concerns on the environmental problems that occur from time to time, such as the frequent occurrence of environmental-based issues, scholars are more conscious of the peoples' actions on related environmental specific issues (Maloney \& Ward, 1973). Thus, there is a need to convince inhabitants to imbibe environmentally friendly behaviour. Ajzen and Fishbein (1980) suggested that a universal attitude such as EC does not influence a particular behaviour directly but inversely. Several past studies have found a positive and significant relationship between EC and behavioural intention to use green products (Lin \& Huang, 2012; Sujata et al., 2019; Zhao et al., 2014). The EC is considered a solid cognitive factor to predict behavioural intention to purchase green products (Zhang et al., 2019). All the accessible empirical researches highlighted that EC favourably leads to positive behavioural intention to engage in pro-environmental behaviour and make effective decisions in purchasing green products. Hence, these posit the hypotheses below:

Hypothesis 7a: Environmental Concern will have a positive and significant influence on Green Attitude for behavioural intention to adopt Green-IT.

Hypothesis 7b: Environmental Concern will have a positive and significant influence on Subjective Norm for behavioural intention to adopt Green-IT.

Hypothesis 7c: Environmental Concern will have a positive and significant influence on Perceived Behaviour for behavioural intention to adopt Green-IT. 


\section{MATERIALS AND METHODS}

\section{Research Design}

This study employed a positivist approach to advance the hypotheses, a priori assumptions to be statistically tested in the comprehensive study to validate the proposed model. This positivist method is selected because it concentrates on testing the concept (Brierley, 2017). It was utilised to validate the model's relationships by relating independent variables with dependent variables to adopt Green-IT. For this pilot study, the non-random purposive sampling technique was used. The study targets only the decision-makers in the manufacturing industries. It is a non-probability sampling technique, which guarantees the trust and proficiency of the informant (Tongco, 2007). Purposive sampling was the preferred method as the selection of the participants will be based on those who were fit to participate in the study. A survey was employed to gather the preliminary data from the targeted population of decision-makers in one of the manufacturing industries. The survey was developed according to the Norm Activation Model (NAM) by Schwartz (1977) and Theory of Planned Behaviour (TPB) by Ajzen and Fishbein (1980).

The primary data collection conducted later will be selecting the three top industries due to their expectation to be leading in substantial areas. These areas include amenities, infrastructure, environmental sustainability, and technology. Decision-makers also agree with the continuously changing environmental guidelines, among others. However, for this study, only one industry was selected as a case. The focus of the pilot study is to develop and validate the model and the instrument, and this data will not be included in the principal analysis. The study further used only samples obtained among the groups of decision-makers. Sampling is essential as it determines that more sample points attained could support analyses of diverse variables (Etikan et al., 2016). Additionally, every individual in the sampling is given an equal chance of being chosen as a respondent (Atkinson et al., 2005).

\section{Data Collection Instrument}

The instrument for this study is a constructed and validated questionnaire. The pilot study intends to get different insights from various decision-makers and ensure that the study is feasible. Six experts validated the survey instrument prior to the pilot study, which helped remove ambiguity. The instrument titled 'Intention to Adopt Green Information Technology Survey Questionnaire (INAGITEQ)' was divided into two (2) sections, A and B. Section A contains items to assess respondents' general demographic information and includes gender, years of experience, educational attainment, and others. Section B contains items to measure the eight (8) constructs to develop the Behavioural Model for Decision-Makers towards the Intention to Adopt Green Information Technology. All the items generated were 
developed using established procedures in the literature and the stakeholders' perspectives, who are specialists in the field of this study.

\section{Intention to use the Green-IT Measures}

The Intention to Adopt Green Information Technology Survey Questionnaire consists of eight (8) dimensions in line with updated measurement items from Zhu et al. (2013), Manavalan and Jayakrishna (2019), and Zhu et al., (2013). These dimensions are Green-IT Attitude, Subjective Norm, Ascription of Responsibility, Aware of Consequences, Personal Norm, Intention to Adopt, Environmental Concern, and Perceived Behavioural Control, with 40 items measuring the construct distributed among the eight (8) dimensions. A Fivepoint Likert scale (5=Strongly Disagree, 2=Disagree, 3=Neutral, 4=Agree, 5=Strongly Agree) was used to measure the extent to which they perceived their intention to use Green-IT, supported by the 40 items in the questionnaire. After several modifications, the instrument was subjected to content validity, construct validity, and reliability. The reports of construct validity and reliability are presented in this paper. The distributions of items within the dimensions are presented in Table 1.

Table 1

The measure of Intention to Adopt Green Information Technology

\begin{tabular}{lll}
\hline SN & Dimension/Construct & Measurement Items \\
\hline 1 & Attitude & ATT1, ATT2, ATT3, ATT4, ATT5 \\
2 & Subjective Norm & SN1, SN2, SN3, SN4, SN5 \\
3 & Ascription of Responsibility & AR1, AR2, AR3, AR4, AR5 \\
4 & Aware of Consequences & AC1, AC2, AC3, AC4, AC5 \\
5 & Personal Norm & PN1, PN2, PN3, PN4, PN5 \\
6 & Intention to Adopt & INT1, INT2, INT3, INT4, INT5 \\
7 & Environmental Concern & EC1, EC2, EC3, EC4, EC5 \\
8 & Perceive Behavioural Control & PBC1, PBC2, PBC3, PBC4, PBC5 \\
\hline
\end{tabular}

\section{Participants}

A pilot test consisted of thirty (30) respondents was conducted to achieve the construct validity and the reliability of the questionnaire. According to Baker et al. (2019), a sample size of $10-20 \%$ of the study's actual sample size is considered a reasonable number to participate in a pilot study. The sample size of the actual study is 280 decision-makers. Thus, 30 respondents represent about $10 \%$ of the actual sample size for the main study (280). The 30 decision-makers in the top three manufacturing industries in Nigeria were 
selected using a purposive sampling procedure, which is a non-probability sampling approach. In the purposive sampling procedure, the researcher selects a "typical group" of individuals who might represent the larger population and then collects data from this group. This feature makes them well suited to small-scale, in-depth studies, as we will go on to show (Creswell \& Plano-Clark, 2007). This purposive sampling involves identifying and selecting individuals or groups of individuals that are exceptionally knowledgeable about or experienced with a phenomenon of interest (Creswell \& Plano-Clark, 2007). In addition to knowledge and experience, Kothari et al. (2020) note the importance of availability and willingness to participate and the ability to communicate experiences and opinions in an articulate, expressive, and reflective manner. The demographic information is presented in Table 2 .

\section{Administration and Data Analysis}

Before the field administration of the instrument for validation purposes, several processes were followed, including content validation by experts, identification of target population for the pilot study selecting the appropriate sample, administration of the draft instrument, and reliability analysis, as reported. Thus, to examine the internal consistency reliability of the research instrument in this study, the data collected from the pilot testing was analysed using the SPSS 25 software and the Partial Least Squares Structural Equation Modelling (PLS-SEM) approach using SmartPLS to conduct a test on the reliability of the instrument by assessing the measurement model at both initial and modified levels. The results of the analysis provide preliminary information on whether the research instrument is suitable or otherwise.

Table 2

Demographic information of the respondents

\begin{tabular}{llcc}
\hline & Variable Level & Frequency (n) & Percentage (\%) \\
\hline \multirow{2}{*}{ Male } & Female & 20 & 66.7 \\
& $21-25$ years & 10 & 33.3 \\
& $26-30$ years & 9 & 30.0 \\
\multirow{2}{*}{} & $31-35$ years & 13 & 43.3 \\
& More than 35 & 5 & 16.7 \\
& & 3 & 10.0 \\
\hline
\end{tabular}


Table 2 (Continued)

\begin{tabular}{|c|c|c|c|}
\hline & Variable Level & Frequency (n) & Percentage (\%) \\
\hline \multirow{3}{*}{ 总 } & College & 4 & 13.3 \\
\hline & High school & 4 & 13.3 \\
\hline & University & 22 & 73.3 \\
\hline \multirow{4}{*}{ } & Less than 2 years & 15 & 50.0 \\
\hline & Less than 4 years & 3 & 10.0 \\
\hline & $4-5$ years & 8 & 26.7 \\
\hline & 9 years and above & 4 & 13.3 \\
\hline \multirow{3}{*}{$\frac{0}{\mathscr{2}}$} & Lower Manager & 26 & 86.7 \\
\hline & Middle Manager & 2 & 6.7 \\
\hline & Top Manager & 2 & 6.7 \\
\hline
\end{tabular}

\section{RESULTS AND DISCUSSIONS}

\section{Summary Statistics}

The scale reliability was used to estimate the reliability of the "Intention to Adopt Green Information Technology Survey Questionnaire (INAGITEQ)'”. The summary statistics are the descriptive information generated using descriptive statistical analyses. The summary of the statistics is presented in Table 3. The results show Mean, Minimum, Maximum, and Variance.

Table 3

Summary of Item Statistics

\begin{tabular}{llccccc}
\hline SN & $\begin{array}{l}\text { Dimension/ } \\
\text { Construct }\end{array}$ & Mean & Minimum & Maximum & Variance & N of Items \\
\hline 1 & Green-IT Attitude & 3.88 & 3.80 & 3.93 & .004 & 5 \\
2 & Subjective Norm & 3.55 & 3.47 & 3.63 & .004 & 5 \\
3 & Ascription of & 3.68 & 3.63 & 3.70 & .001 & 5 \\
& Responsibility & & & & & \\
\hline
\end{tabular}


Table 3 (Continued)

\begin{tabular}{llccccc}
\hline SN & $\begin{array}{l}\text { Dimension/ } \\
\text { Construct }\end{array}$ & Mean & Minimum & Maximum & Variance & N of Items \\
\hline 4 & $\begin{array}{l}\text { Aware of } \\
\text { Consequences }\end{array}$ & 4.00 & 3.17 & 4.27 & .221 & 5 \\
5 & $\begin{array}{l}\text { Personal Norm } \\
\text { Intention to }\end{array}$ & 3.57 & 3.53 & 3.60 & .001 & 5 \\
6 & 3.61 & 3.57 & 3.70 & .004 & 5 \\
7 & $\begin{array}{l}\text { Adopt } \\
\text { Environmental }\end{array}$ & 3.59 & 3.53 & 3.67 & .003 & 5 \\
8 & $\begin{array}{l}\text { Concern } \\
\text { Perceived }\end{array}$ & 3.79 & 3.57 & 4.57 & .192 & 5 \\
\hline
\end{tabular}

\section{Evaluating the Measurement Model}

To assess the measurement model in this study, Partial-Least Square Structural Equation Modelling Approach was applied using SmartPLS 3.0 software. The central emphasis in assessment and goodness of the proposed measurement model is to assess the reliability and construct validity. Hair et al. (2017) defined construct validity as the correspondence between constructs and their indicators. It can also be seen as a necessary condition for developing and testing theory (Jarvis et al., 2003). The construct validity can be evaluated via discriminant and convergent validity. The measurement model of the study's constructs was validated in two major stages, which are (a) the Initial measurement model and (b) the Modified measurement model.

\section{Initial and Modified Measurement Model}

The proposed measurement model of the constructs in this research was assessed through item loadings, composite reliability (CR), and the average variance extracted (AVE). Item loadings of at least 0.7 showed acceptable indicator reliability for the measurement model. In addition, the factor loadings of the 40 items measuring eight (8) sub-constructs were assessed to validate the initial measurement model,

The assessment of the initial measurement model presents the indicators measuring the construct based on the analysis. Based on the analysis results measuring the construct of Intention to Adopt Green Information Technology, nine (9) items out of the 40 items measuring the constructs showed loadings of less than 0.7 , indicating unsatisfactory loading, which violates the model factor loading requirement of 0.7 . However, all the remaining 31 items showed a factor of 0.7 and above, satisfying the requirement (Hair et al., 2017). 
Thus, the nine (9) items which failed the indicator reliability need to be deleted from the model. The PLS algorithm was rerun for the indicator items with external loadings of less than the threshold value of 0.7 ,

In line with the recommendation of Hair et al. (2017), if removing a particular item leads to an improvement in AVE and CR values, deletion of that item is essential. Hence, after conducting the PLS algorithm (Figure 2), the results showed that removing all the nine items improved the values of CR and AVE. Lastly, the remaining items were above the threshold by removing the nine poor items with external loadings of values lower than 0.70 . The results of the indicator reliability measurement after removing the poor items are presented in Table 4.

Table 4

Modified Indicator Loadings

\begin{tabular}{|c|c|c|c|}
\hline SN & Construct & Measurement Items & Outer Loadings \\
\hline \multirow[t]{4}{*}{1} & Attitude & ATT1 & 0.800 \\
\hline & & ATT2 & 0.822 \\
\hline & & ATT4 & 0.785 \\
\hline & & ATT5 & 0.847 \\
\hline \multirow[t]{4}{*}{2} & Subjective Norm & SN1 & 0.986 \\
\hline & & SN3 & 0.947 \\
\hline & & SN4 & 0.943 \\
\hline & & SN5 & 0.987 \\
\hline \multirow[t]{3}{*}{3} & $\begin{array}{l}\text { Perceived Behavioural } \\
\text { Control }\end{array}$ & $\mathrm{PBC} 1$ & 0.990 \\
\hline & & $\mathrm{PBC} 2$ & 1.000 \\
\hline & & $\mathrm{PBC} 5$ & 0.990 \\
\hline \multirow[t]{4}{*}{4} & Aware of Consequences & $\mathrm{AC} 1$ & 0.981 \\
\hline & & $\mathrm{AC} 3$ & 0.968 \\
\hline & & $\mathrm{AC} 4$ & 0.945 \\
\hline & & AC5 & 0.989 \\
\hline \multirow[t]{4}{*}{5} & Personal Norm & PN1 & 0.988 \\
\hline & & PN3 & 0.965 \\
\hline & & PN4 & 0.943 \\
\hline & & PN5 & 0.979 \\
\hline \multirow[t]{4}{*}{6} & Ascription of Responsibility & AR1 & 0.981 \\
\hline & & AR3 & 0.967 \\
\hline & & AR4 & 0.945 \\
\hline & & AR5 & 0.980 \\
\hline
\end{tabular}


Table 4 (Continued)

\begin{tabular}{llcc}
\hline SN & Construct & Measurement Items & Outer Loadings \\
\hline 7 & Environmental Concern & EC1 & 0.984 \\
& & EC3 & 0.950 \\
& & EC4 & 0.939 \\
& \multirow{2}{*}{ Intention to Adopt } & EC5 & 0.988 \\
& & INT1 & 0.988 \\
& & INT3 & 0.946 \\
& & INT4 & 0.950 \\
& INT5 & 0.987 \\
\hline
\end{tabular}

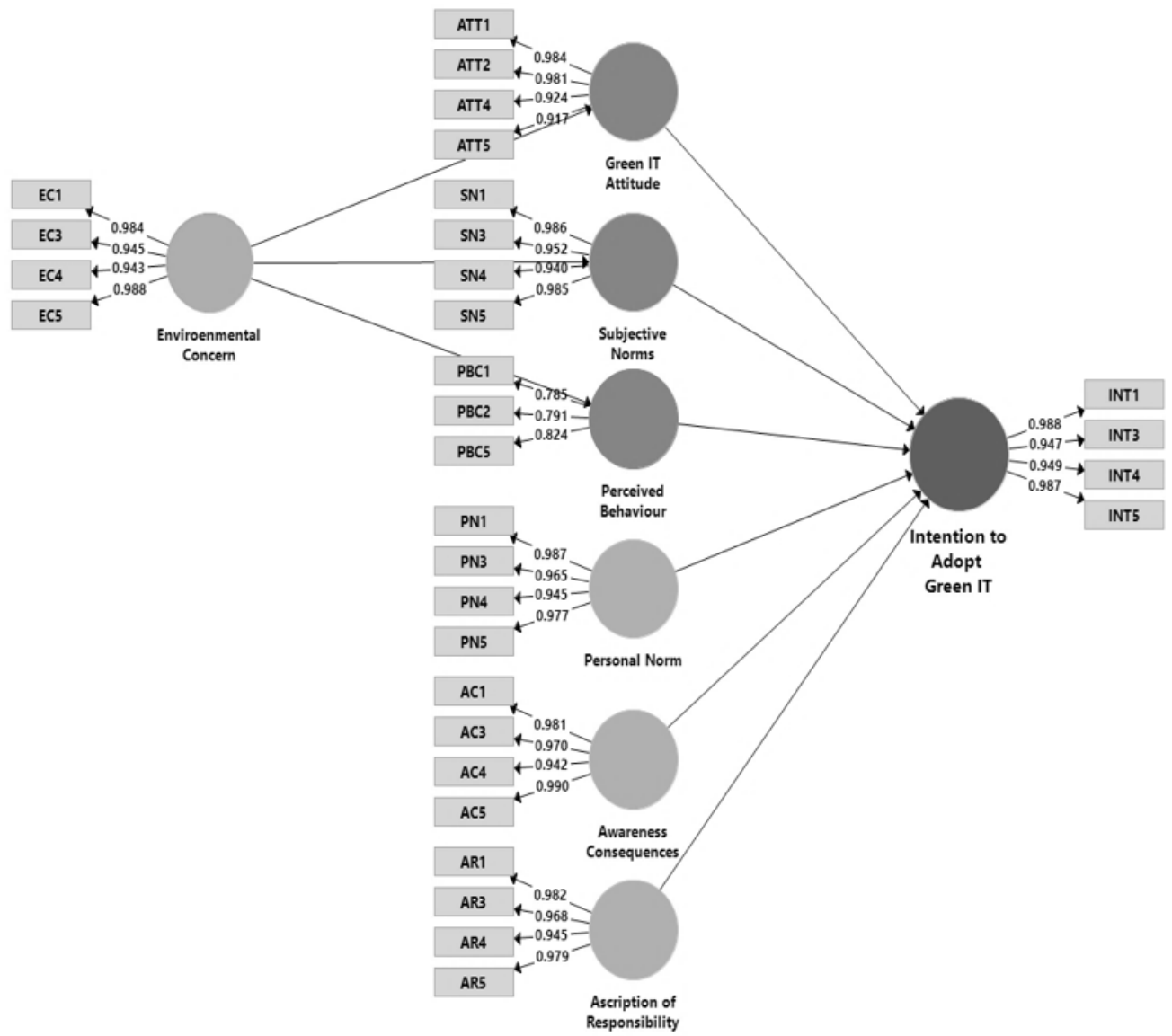

Figure 2. Modified Measurement Model 


\section{Internal Consistency Reliability}

The assessment of the internal consistency reliability was performed alongside the benchmarks of composite reliability and Cronbach's alpha $(\alpha)$. As presented in Table 5, all identified constructs of the study met the satisfactory criteria of Cronbach's alpha and CR, which are supposed to be higher than 0.70 . Thus, the results specify that all the indicators used to signify the constructs are reliable.

Table 5

Internal Consistency Reliability

\begin{tabular}{llcc}
\hline SN & Construct & Cronbach's Alpha & $\begin{array}{c}\text { Composite } \\
\text { Reliability }\end{array}$ \\
\hline 1 & Attitude & 0.830 & 0.887 \\
2 & Subjective Norm & 0.976 & 0.982 \\
3 & Perceived Behavioural Control & 0.993 & 0.996 \\
4 & Aware of Consequences & 0.980 & 0.985 \\
5 & Personal Norm & 0.978 & 0.984 \\
6 & Ascription of Responsibility & 0.978 & 0.984 \\
7 & Environmental Concern & 0.976 & 0.982 \\
8 & Intention to Adopt & 0.978 & 0.983 \\
\hline
\end{tabular}

\section{Convergent Validity}

The convergent validity of the study's constructs is achieved by evaluating the values of AVE for each construct. In line with recommendations by Hair et al. (2017), this investigation considered the estimate of at least 0.5 as a good value for the AVE. As displayed in Table 6 , the AVE values of all constructs exceeded the minimum value of 0.5 , which means there is no issue regarding the convergent validity of the proposed measurement model.

Table 6

Convergent Validity

\begin{tabular}{llc}
\hline SN & Construct & Average Variance Extracted (AVE) \\
\hline 1 & Attitude & 0.663 \\
2 & Subjective Norm & 0.933 \\
3 & Perceived Behavioural Control & 0.987 \\
4 & Aware of Consequences & 0.943 \\
5 & Personal Norm & 0.938 \\
6 & Ascription of Responsibility & 0.938 \\
7 & Environmental Concern & 0.932 \\
8 & Intention to Adopt & 0.937 \\
\hline
\end{tabular}




\section{Discriminant Validity}

In line with the Voorhees et al. (2016) principle, the discriminant validity of the measurement model in this study was implemented. Any proposed measurement model of a study is regarded to have obtained substantial discriminant validity if the square roots of the AVE are higher than the association or correlations between the identified measure and all other measures in the model. Therefore, the evaluation was conducted on the discriminant validity for each factor.

The results indicated that all the AVE square roots were higher than the off-diagonal elements within their corresponding column and row. The values highlighted in bold in Table 7 show the values of cross-loadings and the Voorhees et al. (2016) criteria assessment. As indicated, the AVE's square roots and other values signify the intercorrelation between the constructs. This indicates that Voorhees et al., (2016) criterion are met. In this situation, the discriminant validity is achieved as the correlation among different constructs was low. Thus, with the satisfaction and assurance of discriminant validity, all the adjustments of the measurement model have been completed and can be used to run the structural model and test the hypotheses in this study.

Table 7

Discriminant validity (Fornell-Larcker's Standard)

\begin{tabular}{lcccccccc}
\hline & AC & AR & ATT & EC & INT & PBC & PN & SN \\
\hline AC & $\mathbf{0 . 9 7 1}$ & & & & & & & \\
AR & 0.367 & $\mathbf{0 . 9 6 9}$ & & & & & & \\
ATT & 0.061 & 0.075 & $\mathbf{0 . 8 1 4}$ & & & & & \\
EC & 0.381 & 0.381 & 0.043 & $\mathbf{0 . 9 6 5}$ & & & & \\
INT & 0.189 & 0.408 & 0.047 & 0.198 & $\mathbf{0 . 9 6 8}$ & & & \\
PBC & -0.046 & 0.180 & 0.283 & -0.047 & 0.082 & $\mathbf{0 . 9 9 3}$ & & \\
PN & 0.365 & 0.591 & 0.067 & 0.379 & 0.389 & 0.169 & $\mathbf{0 . 9 6 9}$ & \\
SN & 0.367 & 0.193 & 0.163 & 0.393 & 0.062 & -0.026 & 0.183 & $\mathbf{0 . 9 6 6}$ \\
\hline
\end{tabular}

\section{CONCLUSION}

This study intends to find elements that influence the decision-makers to have intention in Green-IT adoption, analyse the relationship between the factors, and develop a valid and reliable model for adopting Green-IT to tackle environmental degradation. The findings from this preliminary study provide initial support for the model constructs and instruments in the assessment of factors influencing decision-makers to have the intention to adopt Green-IT to mitigate environmental degradation. The reliability coefficient for 
the model constructs was established with a Cronbach's alpha value greater than 0.80 for all the constructs, higher than the minimum recommended value of 0.70 indicators (Hair et al., 2017; Akman \& Mishra, 2014). The convergent and discriminant validity of all the constructs was established through the AVE and CR statistics. After deleting some poor misfit items, the AVE and CR values for all constructs were above the recommended minimum threshold.

Thus, all the constructs in the proposed model were appropriate for the final model to be validated in the main/full study. Following the comments and suggestions from academic experts and respondents to the pilot questionnaire, and the analysis is shown above, a final instrument has been designed for the proposed full-scale study. Moreover, the validation report of the Intention to Adopt Green Information Technology survey questionnaire is proposed to develop a Behavioural Model for Decision-Makers towards the Intention to Adopt Green Information Technology. Therefore, the results of the pilot studies show that, based on the established standards, the instrument is valid and reliable and can be considered a valid measuring instrument to collect relevant data in the full-scale study.

Previous researches on Green-IT have stressed the importance of Green-IT adaptation, especially in the decision-making process of mitigating environmental degradation and improvement in the manufacturing sector. Since the IT industry significantly impacts the environment, its utilisation growth is caused by massive energy consumption and reducing natural resources (Sanita et al., 2018). Based on previous research on the adoption of Green-IT (Przychodzen et al., 2018), introducing Green-IT to decision-makers has altered the manufacturing industries from traditional to modern. As a result, there has been rapid exhaustion of natural resources and awareness of environmental deterioration in the past (Przychodzen et al., 2018). It has led to an increase in the need for environmental responsibility. Therefore, the adoption of Green-IT by firms and industries has been a major topic among academics, decision-makers, and practitioners ( Dalvi-Esfahani et al., 2017a; Dalvi-Esfahani et al., 2017b; Masri \& Jaaron, 2017). Accordingly, Green-IT involves the efficient and practical design, manufacture, and use of computers, servers, and various peripherals to reduce environmental damage (Cai et al., 2013; Yang et al., 2019). Therefore, Green-IT is key for dealing with environmental damage (Przychodzen et al., 2018). For example, Dalvi-Esfahani et al. (2017a \& 2017b) indicate that Green-IT adoption factors such as Environmental Concern, Green-IT Attitude, and Subjective Norm are significant when discussing the intention of individuals to adopt technologies. Asadi et al., (2019) argue that Perceived Behaviour Control, Personal Norm, Awareness of Consequence, and Ascription of Responsibility can also influence intention for adoption, as behavioural intent is explained for technology adoption.

The development and validation of the model and instrument is the first phase to evaluate the related factors that influence the stakeholders' behavioural intention to 
adopt Green-IT. The investigator aims to utilise the instruments validated in this study to implement the survey in the main study using selected target groups of IT professionals who are the decision-makers in the Nigerian manufacturing industries. The effect of each construct in the proposed model on the adoption of Green-IT in Nigerian manufacturing industries will be examined. Their significance in the model will be validated by testing the proposed hypotheses using Partial Least Square Structural Equation Modelling (PLSSEM). A final validated model will be created, used in future Green-IT adoption research in similar contexts. The model can also be used in future studies on Green-IT adoption in other sectors such as educational institutions, small and medium scale businesses, public services, and government agencies in Nigeria and beyond.

The results from the full-scale study will contribute to developing a context-specific model that can be used to examine Green-IT adoption and other technology-specific sectors in manufacturing industries in Nigeria and other developing nations. It will also contribute to the literature in Green-IT through relevant empirical evidence from the study's findings and provide the decision-makers with the basis for making specific decisions in the sector. In addition, the findings from the proposed study will be of significant importance to ITbased practitioners who are primarily service providers with valuable information and valid data, supported with scientific evidence to be used for any project in Green-IT. Finally, the study will contribute to the ongoing research into the best IT-based adoption models relevant in developing nations.

\section{ACKNOWLEDGMENT}

The author sincerely acknowledges the Universiti Teknologi Malaysia for providing space and facilities to support this research. He also thank other experts who contribute and provide support to this study.

\section{REFERENCES}

Aboelmaged, M., \& Hashem, G. (2019). Absorptive capacity and green innovation adoption in SMEs: The mediating effects of sustainable organisational capabilities. Journal of Cleaner Production, 220, 853-863. https://doi.org/10.1016/j.jclepro.2019.02.150

Abrahamse, W., \& Steg, L. (2009). How do socio-demographic and psychological factors relate to households' direct and indirect energy use and savings? Journal of Economic Psychology, 30(5), 711-720. https://doi. org/10.1016/j.joep.2009.05.006

Agag, G. (2019). Understanding the determinants of guests' behaviour to use green P2P accommodation. International Journal of Contemporary Hospitality Management, 31(9), 3417-3446. https://doi. org/10.1108/ijchm-09-2018-0755

Ainin, S., Jaafar, N. I., \& Dezdar, S. (2015). Consideration of future consequences among managers in Iran and Malaysia. Futures, 71, 29-35. https://doi.org/10.1016/j.futures.2015.06.003 
Ajzen. (1991). Measuring oral health behaviour in Flemish health care workers: An application of the theory of planned behaviour. Community Dental Health, 25(2), 107-114. https://doi.org/10.1922/ CDH_2120VandenBroucke08

Ajzen, I., \& Fishbein, M. (1980). Understanding attitudes and predicting social behaviour. Prentice-Hall.

Akman, I., \& Mishra, A. (2014). Green information technology practices among IT professionals: Theory of planned behavior perspective. Problemy Ekorozwoju, 9(2), 47-54.

Akman, I., \& Mishra, A. (2015). Sector diversity in green information technology practices: Technology acceptance model perspective. Computers in Human Behavior, 49, 477-486. https://doi.org/10.1016/j. chb.2015.03.009

Anthony, B., Majid, M. A., \& Romli, A. (2020). A generic study on green IT/IS practice development in collaborative enterprise: Insights from a developing country. Journal of Engineering and Technology Management - JET-M, 55(February), Article 101555. https://doi.org/10.1016/j.jengtecman.2020.101555

Anthony Jr, B. (2019). Green information system integration for environmental performance in organizations. Benchmarking: An International Journal, 26(3), 1033-1062. https://doi.org/10.1108/BIJ-05-2018-0142

Armitage, C. J., \& Conner, M. (2001). Efficacy of the theory of planned behaviour: A meta-analytic review E Y cacy of the theory of planned behaviour : A meta-analytic review. (July 2017), 471-499. https://doi. org/10.1348/014466601164939

Arvola, A., Vassallo, M., Dean, M., Lampila, P., Saba, A., Lähteenmäki, L., \& Shepherd, R. (2008). Predicting intentions to purchase organic food: The role of affective and moral attitudes in the theory of planned behaviour. Appetite, 50(2-3), 443-454. https://doi.org/10.1016/j.appet.2007.09.010

Asadi, S., Hussin, A. R. C., Dahlan, H. M., \& Yadegaridehkordi, E. (2015). Theoretical model for green information technology adoption. ARPN Journal of Engineering and Applied Sciences, 10(23), 1772017729.

Asadi, S., Nilashi, M., Safaei, M., Abdullah, R., Saeed, F., Yadegaridehkordi, E., \& Samad, S. (2019). Investigating factors influencing decision-makers' intention to adopt green IT in Malaysian manufacturing industry. Resources, Conservation and Recycling, 148(March), 36-54. https://doi.org/10.1016/j. resconrec.2019.04.028

Atkinson, M. J., Kumar, R., Cappelleri, J. C., \& Mass, S. L. (2005). Hierarchical construct validity of the treatment satisfaction questionnaire for medication (TSQM Version II) among outpatient pharmacy consumers. Value in Health, 8(SUPPL. 1), S9-S24. https://doi.org/10.1111/j.1524-4733.2005.00066.x

Baker, D. H., Vilidaite, G., Lygo, F. A., Smith, A. K., Flack, T. R., Gouws, A. D., \& Andrews, T. J. (2019). Power contours: Optimising sample size and precision in experimental psychology and human neuroscience. arXiv.org.

Bodur, M., \& Sarigöllü, E. (2005). Environmental sensitivity in a developing country: Consumer classification and implications. Environment and Behavior, 37(4), 487-510. https://doi.org/10.1177/0013916504269666

Brandvik, P. J., Storey, C., Davies, E. J., \& Johansen, Ø. (2019). Combined releases of oil and gas under pressure: The influence of live oil and natural gas on initial oil droplet formation. Marine Pollution Bulletin, 140(February), 485-492. https://doi.org/10.1016/j.marpolbul.2019.01.036 
Brierley, J. A. (2017). The role of a pragmatist paradigm when adopting mixed methods in behavioural accounting research. International Journal of Behavioural Accounting and Finance, 6(2), 140-154. https:// doi.org/10.1504/ijbaf.2017.10007499

Buba, A. K., \& Ibrahim, O. (2020). Behavioural model for decision-makers' intention to adopt green information technology in Nigerian manufacturing industries. Science Proceedings Series, 2(2), 166-171. https://doi. org/10.31580/sps.v2i2.1721

Burns, S., \& Roberts, L. (2013). Applying the theory of planned behaviour to predicting online safety behaviour. Crime Prevention and Community Safety, 15(1), 48-64. https://doi.org/10.1057/cpcs.2012.13

Cai, S., Chen, X., \& Bose, I. (2013). Exploring the role of IT for environmental sustainability in China: An empirical analysis. International Journal of Production Economics, 146(2), 491-500. https://doi. org/10.1016/j.ijpe.2013.01.030

Chen, H. G., \& Chang, J. (2014a). A study on green IT adoption. Computer Science and Information Technology, 2(8), 315-323. https://doi.org/10.13189/CSIT.2014.020801

Chen, H. G., \& Chang, J. (2014b). Exploring affecting factors on green IT adoption. In International Conference on Knowledge Management in Organizations (pp. 205-218). Springer. https://doi.org/10.1007/978-3319-08618-7

Chen, M. F., \& Tung, P. J. (2014). Developing an extended theory of planned behavior model to predict consumers' intention to visit green hotels. International Journal of Hospitality Management, 36, 221-230. https://doi.org/10.1016/j.ijhm.2013.09.006

Chow, W. S., \& Chen, Y. (2009). Intended belief and actual behavior in green computing in Hong Kong. Journal of Computer Information Systems, 50(2), 136-141. https://doi.org/10.1080/08874417.2009.11645392

Creswell, J. W., \& Plano-Clark, V. (2007). Designing and constructing mixed methods research. Sage Publication.

Dalvi-Esfahani, M., Ramayah, T., \& Nilashi, M. (2017a). Modelling upper echelons' behavioural drivers of green IT/IS adoption using an integrated interpretive structural modelling - Analytic network process approach. Telematics and Informatics, 34(2), 583-603. https://doi.org/10.1016/j.tele.2016.10.002

Dalvi-Esfahani, M., Ramayah, T., \& Rahman, A. A. (2017b). Moderating role of personal values on managers' intention to adopt green IS: Examining norm activation theory. Industrial Management and Data Systems, 117(3), 582-604. https://doi.org/10.1108/IMDS-02-2016-0049

de Groot, J., \& Steg, L. (2009). Morality and pro-social behaviour: the role of awareness, responsibility and norms in the norm activation model. Journal of Social Psychology, 31(4), 425-449.

De Luis, M. M., Cruz, A. J. A., Arcia, A. V. U., \& Márquez, C. Y. (2015). Green information technology influence on car owners' behavior: Considerations for their operative support in collaborative eLearning and social networks. Computers in Human Behavior, 51, 792-802. https://doi.org/10.1016/j.chb.2014.11.085

Dezdar, S. (2017). Green information technology adoption: Influencing factors and extension of theory of planned behavior. Social Responsibility Journal, 13(2), 292-306. https://doi.org/10.1108/SRJ-05-20160064 
Esfahani, M. D., Rahman, A. A., \& Zakaria, N. H. (2015). Influence processes for practicing green information technology: Elaboration likelihood model. In Pacific Asia Conference on Information Systems, PACIS 2015 (pp. 1-11). AIS Electronic Library (AISeL).

Etikan, I., Musa, S. A., \& Alkassim, R. S. (2016). Comparison of convenience sampling and purposive sampling. American Journal of Theoretical and Applied Statistics, 5(1), 1-4. https://doi.org/10.11648/j. ajtas.20160501.11

Gandhi, N. S., Thanki, S. J., \& Thakkar, J. J. (2018). Ranking of drivers for integrated lean-green manufacturing for Indian manufacturing SMEs. Journal of Cleaner Production, 171(June 2008), 675-689. https://doi. org/10.1016/j.jclepro.2017.10.041

Guo, L., Xu, Y., Liu, G., Wang, T., \& Du, C. (2019). Understanding firm performance on green sustainable practices through managers' ascribed responsibility and waste management: Green self-efficacy as moderator. Sustainability (Switzerland), 11(18), 1-16. https://doi.org/10.3390/su11184976

Hair, J. F., Hult, G. T. M., Ringle, C. M., Sarstedt, M., \& Thiele, K. O. (2017). Mirror, mirror on the wall: A comparative evaluation of composite-based structural equation modeling methods. Journal of the Academy of Marketing Science, 45(5), 616-632. https://doi.org/10.1007/s11747-017-0517-x

Han, H., Hwang, J., Kim, J., \& Jung, H. (2015). Guests' pro-environmental decision-making process: Broadening the norm activation framework in a lodging context. International Journal of Hospitality Management, 47, 96-107. https://doi.org/10.1016/j.ijhm.2015.03.013

Harland, P., Staats, H., \& Wilke, H. A. M. (2007). Situational and personality factors as direct or personal norm mediated predictors of pro-environmental behavior: Questions derived from norm-activation theory. Basic and Applied Social Psychology, 29(4), 323-334. https://doi.org/10.1080/01973530701665058

Huda, M. (2019). Empowering application strategy in the technology adoption: Insights from professional and ethical engagement. Journal of Science and Technology Policy Management, 10(1), 172-192. https://doi. org/10.1108/JSTPM-09-2017-0044

Jarvis, C. B., Mackenzie, S. B., Podsakoff, P. M., Giliatt, N., \& Mee, J. F. (2003). a critical review of construct indicators and measurement model misspecification in marketing and consumer research. Journal of Consumer Research, 30(2), 199-218. https://doi.org/10.1086/376806

Juschten, M., Jiricka-Pürrer, A., Unbehaun, W., \& Hössinger, R. (2019). The mountains are calling! An extended TPB model for understanding metropolitan residents' intentions to visit nearby alpine destinations in summer. Tourism Management, 75(May 2018), 293-306. https://doi.org/10.1016/j.tourman.2019.05.014

Kim, J. J., \& Hwang, J. (2020). Merging the norm activation model and the theory of planned behavior in the context of drone food delivery services: Does the level of product knowledge really matter? Journal of Hospitality and Tourism Management, 42(June 2019), 1-11. https://doi.org/10.1016/j.jhtm.2019.11.002

Kong, T., Feng, T., \& Ye, C. (2016). Advanced manufacturing technologies and green innovation: The role of internal environmental collaboration. Sustainability (Switzerland), 8(10), 9-11. https://doi.org/10.3390/ su8101056

Koo, C., Wati, Y., \& Jung, J. J. (2011). Examination of how social aspects moderate the relationship between task characteristics and usage of social communication technologies (SCTs) in organizations. International Journal of Information Management, 31(5), 445-459. https://doi.org/10.1016/j.ijinfomgt.2011.01.003 
Kothari, A., Mccutcheon, C., Boland, L., \& Graham, I. D. (2020). How we work together. Integrated Knowledge Translation Research Network.

Lauper, E., Moser, S., Fischer, M., \& Matthies, E. (2014). Explaining car drivers' intention to prevent roadtraffic noise: An application of the norm activation model. Environment and Behavior, 48(6), 826-853. https://doi.org/10.1177/0013916515570476

Lin, P. C., \& Huang, Y. H. (2012). The influence factors on choice behavior regarding green products based on the theory of consumption values. Journal of Cleaner Production, 22(1), 11-18. https://doi.org/10.1016/j. jclepro.2011.10.002

Lopes, J. R. N., de Araújo Kalid, R., Rodríguez, J. L. M., \& Ávila Filho, S. (2019). A new model for assessing industrial worker behavior regarding energy saving considering the theory of planned behavior, norm activation model and human reliability. Resources, Conservation and Recycling, 145, 268-278. https:// doi.org/10.1016/j.resconrec.2019.02.042

Maloney, M. P., \& Ward, M. P. (1973). Ecology: Let's hear from the people: An objective scale for the measurement of ecological attitudes and knowledge. American Psychologist, 28(7), 583-586. https:// doi.org/10.1037/h0034936

Maruthi, G. D., \& Rashmi, R. (2015). Green manufacturing: It's tools and techniques that can be implemented in manufacturing sectors. Materials Today: Proceedings, 2(4-5), 3350-3355. https://doi.org/10.1016/j. matpr.2015.07.308

Manavalan, E., \& Jayakrishna, K. (2019). A review of Internet of Things (IoT) embedded sustainable supply chain for industry 4.0 requirements. Computers and Industrial Engineering, 127(November 2017), 925953. https://doi.org/10.1016/j.cie.2018.11.030

Masri, H. A., \& Jaaron, A. A. M. (2017). Assessing green human resources management practices in Palestinian manufacturing context: An empirical study. Journal of Cleaner Production, 143, 474-489. https://doi. org/10.1016/j.jclepro.2016.12.087

Molla, A., Cooper, V., Corbitt, B., Deng, H., Peszynski, K., \& Yen, S. (2008). E-readiness to G-readiness: Developing a green information technology readiness framework. In ACIS 2008 Proceedings (pp. 669678). AIS Electronic Library (AISeL).

Nallusamy, S., Ganesan, M., Balakannan, K., \& Shankar, C. (2016). Environmental sustainability evaluation for an automobile manufacturing industry using multi-grade fuzzy approach. International Journal of Engineering Research in Africa, 19, 123-129. https://doi.org/10.4028/www.scientific.net/JERA.19.123

Nasri, W., \& Charfeddine, L. (2012). Factors affecting the adoption of Internet banking in Tunisia: An integration theory of acceptance model and theory of planned behavior. Journal of High Technology Management Research, 23(1), 1-14. https://doi.org/10.1016/j.hitech.2012.03.001

Ojo, A. O., Raman, M., \& Downe, A. G. (2019). Toward green computing practices: A Malaysian study of green belief and attitude among information technology professionals. Journal of Cleaner Production, 224, 246-255. https://doi.org/10.1016/j.jclepro.2019.03.237

Onwezen, M. C., Antonides, G., \& Bartels, J. (2013). The norm activation model: An exploration of the functions of anticipated pride and guilt in pro-environmental behaviour. Journal of Economic Psychology, 39, 141-153. https://doi.org/10.1016/j.joep.2013.07.005 
Park, J., \& Ha, S. (2014). Understanding consumer recycling behavior: Combining the theory of planned behavior and the norm activation model. Family and Consumer Sciences Research Journal, 42(3), 278291. https://doi.org/10.1111/fcsr.12061

Pavlou, P. A., \& El Sawy, O. A. (2006). From IT leveraging competence to competitive advantage in turbulent environments: The case of new product development. Information Systems Research, 17(3), 198-227. https://doi.org/10.1287/isre.1060.0094

Przychodzen, W., Gómez-Bezares, F., \& Przychodzen, J. (2018). Green information technologies practices and financial performance - The empirical evidence from German publicly traded companies. Journal of Cleaner Production, 201, 570-579. https://doi.org/10.1016/j.jclepro.2018.08.081

Ramstein, C., Dominioni, G., Ettehad, S., Lam, L., Quant, M., Zhang, J., Mark, L., Nierop, S., Berg, T., Leuschner, P., Merusi, C., Klein, N., \& Trim, I. (2019). State and trends of carbon pricing 2019. The World Bank. https://doi.org/10.1596/978-1-4648-1435-8

Rehman, M. A., \& Shrivastava, R. L. (2013). Green manufacturing (GM): Past, present and future (a state of art review). World Review of Science, Technology and Sustainable Development, 10(1-2-3), 17-55. https:// doi.org/10.1504/WRSTSD.2013.050784

Reyes-Rodríguez, M. L., Rivera-Medina, C. L., Cámara-Fuentes, L., Suárez-Torres, A., \& Bernal, G. (2013). Depression symptoms and stressful life events among college students in Puerto Rico. Journal of Affective Disorders, 145(3), 324-330. https://doi.org/10.1016/j.jad.2012.08.010

Rezaei, R., Safa, L., Damalas, C. A., \& Ganjkhanloo, M. M. (2019). Drivers of farmers' intention to use integrated pest management: Integrating theory of planned behavior and norm activation model. Journal of Environmental Management, 236(August 2018), 328-339. https://doi.org/10.1016/j.jenvman.2019.01.097

Sani, D. A., Shahabi, H., Ahmad, B. A., Mirmokrigh, S., \& Ahmad, B. (2016). Application of geographic information system technology in controlling pipeline vandalism of oil and gas industry. Research Journal of Information Technology, 8(1), 39-46. https://doi.org/10.3923/rjit.2016.39.46

Sanita, F., Udin, Z. M., \& Hasnan, N. (2018). Green IT/S adoption within GSCM in Indonesian construction industry: An elucidation and practice. Journal of Information System and Technology Management, 2(6), 105-116.

Schwartz, S. H. (1977). Normative influences on altruism. In Advances in experimental social psychology (Vol. 10, pp. 221-279). Academic Press. https://doi.org/10.1016/S0065-2601(08)60358-5

Schwartz, H., \& Davis, S. M. (1981). Matching corporate culture and business strategy. Organizational Dynamics, 10(1), 30-48. https://doi.org/10.1016/0090-2616(81)90010-3

Seidel, S., Recker, J., \& Vom Brocke, J. (2013). Sensemaking and sustainable practicing: functional affordances of information systems in green transformations. MIS quarterly, 37(4), 1275-1299.

Singh, M., \& Sahu, G. P. (2020). Towards adoption of green IS: A literature review using classification methodology. International Journal of Information Management, 54(October 2019), Article 102147. https://doi.org/10.1016/j.ijinfomgt.2020.102147

Steg, L., \& de Groot, J. (2010). Explaining prosocial intentions: Testing causal relationships in the norm activation model. British Journal of Social Psychology, 49(4), 725-743. https://doi.org/10.1348/014466609X477745 
Sujata, M., Khor, K. S., Ramayah, T., \& Teoh, A. P. (2019). The role of social media on recycling behaviour. Sustainable Production and Consumption, 20, 365-374. https://doi.org/10.1016/j.spc.2019.08.005

Tongco, M. D. C. (2007). Purposive sampling as a tool for informant selection. Ethnobotany Research and Applications, 5, 147-158. https://doi.org/10.17348/era.5.0.147-158

Voorhees, C. M., Brady, M. K., Calantone, R., \& Ramirez, E. (2016). Discriminant validity testing in marketing: An analysis, causes for concern, and proposed remedies. Journal of the Academy of Marketing Science, 44(1), 119-134. https://doi.org/10.1007/s11747-015-0455-4

Wang, W., Zhang, S., \& Pasquire, C. (2018). Factors for the adoption of green building specifications in China. International Journal of Building Pathology and Adaptation, 36(3), 254-267. https://doi.org/10.1108/ IJBPA-06-2017-0027

Willuweit, L. (2009). Promoting pro-environmental behavior: An investigation of the cross-cultural environmental behavior patterns. The case of Abu Dhabi (MSc Thesis). Stockholm University, Sweden.

Woo, C., Chung, Y., Chun, D., Han, S., \& Lee, D. (2014). Impact of green innovation on labor productivity and its determinants: An analysis of the Korean manufacturing industry. Business Strategy and the Environment, 23(8), 567-576. https://doi.org/10.1002/bse.1807

Yacob, P., Khor, S. C., Jaganathan, M., Maludin, N., \& Nodesan, S. (2018, May 12-13). Small manufacturing firms sustainable green practices: Operationalization of sustainable value framework. In ASIA International Multidisciplinary Conference 2018 (pp. 1-8). Johor Bahru, Malaysia.

Yang, X., Li, Y., \& Kang, L. (2019). Reconciling “doing good” and “doing well” in organizations' green IT initiatives: A multi-case analysis. International Journal of Information Management, (May 2018), Article 102052. https://doi.org/10.1016/j.ijinfomgt.2019.102052

Zhang, L., Fan, Y., Zhang, W., \& Zhang, S. (2019). Extending the theory of planned behavior to explain the effects of cognitive factors across different kinds of green products. Sustainability (Switzerland), 11(15), 1-17. https://doi.org/10.3390/su11154222

Zhang, Y., Wang, Z., \& Zhou, G. (2013). Antecedents of employee electricity saving behavior in organizations: An empirical study based on norm activation model. Energy Policy, 62, 1120-1127. https://oi. org/10.1016/j.enpol.2013.07.036

Zhao, H. H., Gao, Q., Wu, Y. P., Wang, Y., \& Zhu, X. D. (2014). What affects green consumer behavior in China? A case study from Qingdao. Journal of Cleaner Production, 63, 143-151. https://doi.org/10.1016/j. jclepro.2013.05.021

Zhu, Q., Sarkis, J., \& Lai, K. H. (2013). Institutional-based antecedents and performance outcomes of internal and external green supply chain management practices. Journal of Purchasing and Supply Management, 19(2), 106-117. https://doi.org/10.1016/j.pursup.2012.12.001 